\title{
SURTO DE INTOXICAÇÃO DE BOVINOS POR HEXACLOROBENZENO- BHC
}

\section{(Poison by Hexaclorobenzeno- BHC in cattle)}

\section{Wilmar Sachetin Marçal ${ }^{1}$, José Antônio da Silva Fernandes, Maísa Fabiana Menck ${ }^{1}$ \\ ${ }^{1}$ Correspondência: wilmar@uel.br}

RESUmo: Apesar de proibido no Brasil, o Hexaclorobenzeno (BHC) é um dos poluentes ambientais, mais perigosos e sua contaminação pode comprometer o solo, plantas, mananciais hídricos e diferentes criações de animais. Nas propriedades rurais onde são utilizados, não raro, o BHC acaba sendo deixado em locais impróprios, como tulhas e paióis. Outras vezes alguns produtores rurais armazenam esse veneno em barracões desprotegidos, o que pode provocar acidentes para seres vivos, tanto ao homem, como aos animais. Isto foi evidenciado, na prática, numa propriedade rural do município paranaense de Kaloré, estado do Paraná. Além da mortalidade observada em 15 bovinos adultos, foi possível atuar de modo pericial para, ao se fechar o círculo da toxidez, fomentar o poder judiciário com a comprovação do surto e das respectivas consequências.

Palavras-chave: BHC; bovinos; intoxicação

ABSTRACT: In spite of being prohibited in Brazil, hexachlorobenzene (BHC) is one of the most dangerous environmental pollutants and its contamination can compromise the soil, plants, springs and animals. In rural properties where hexachlorobenzene $(\mathrm{BHC})$ is used, often, hexachlorobenzene $(\mathrm{BHC})$ ends up being left in improper places, such as sheds or barns. Other times some farmers store this product in unprotected sheds that can lead to accidents not only for man but also for animals. This was shown up, in practice, in a rural area in the city of Parana in Kalore. Besides the mortality observed in 15 adult adult cattle, it was possible to act in an expert approach in order to closing the toxicity circle providing data to the authorities with proofs.

Key Words: BHC ; cattle; toxicity 


\section{INTRODUÇÃO}

A contaminação ambiental provocada pela aplicação de agrotóxicos pode resultar no desequilíbrio dos ecossistemas, além de causar danos diretos à saúde humana e saúde animal. No Brasil, existem várias áreas contaminadas com resíduos tóxicos, tais como o $\mathrm{BHC}$, um composto organoclorado usado no passado como fungicida, mas que atualmente tem seu uso proibido, devido a sua alta persistência no ambiente e alta capacidade de bioacumulação (NAKAGAWA, ANDRÉA, 2005).

Há muitos anos atrás, o $\mathrm{BHC}$ foi um dos produtos mais utilizados na agricultura para o controle de pragas e tratamento de sementes. As restrições de seu uso foram devido ao fato de ser um dos poluentes ambientais de maior persistência na natureza contaminando solo, plantas, mananciais hídricos, entre outros. Apesar da proibição no Brasil, há ainda muito contrabando que continua viabilizando a entrada desse veneno em várias localidades do país, colocando em risco grandes áreas agrícolas e os seres vivos que habitam nas mesmas.

Nas propriedades rurais que ainda teimam em desobedecer a Lei e utilizar - BHC, parece também não existir qualquer zelo pela estocagem do produto, já que não são raros os relatos de toxidez por esse agrotóxico (CARVALHO et al., 1984; PINTO et al., 1987; KESSABI et al., 1990; NIEWIADOWSKA, ZMUDZKI; SEMENIUK, 1995; MANIRAKIZA et al., 2002; PARDIO et al., 2003 e WALISZEWSKI et al., 2004). O incremento dessa irregularidade vem expondo homens e animais a um risco permanente de intoxicação, sendo de forma voluntária ou involuntária. $\mathrm{Na}$ pecuária, por exemplo, havendo falha de manejo ou deficiência alimentar os animais acabam ingerindo o veneno, com consequências indesejáveis e significativos prejuízos aos produtores rurais. Além de quadros tóxicos que podem afetar rebanhos inteiros de exploração pecuária, há sérios danos ambientais provocados pelo BHC, sem haver, contudo, uma fiscalização rigorosa e contínua (ANDREOLI; FERREIRA, 1998; PASCHOAL, 1983). Muitos desses impactos são imensuráveis e esta constatação, na prática, foi vivenciada em uma propriedade rural do município de Kaloré, estado do Paraná, onde ocorreram vários óbitos de bovinos.

Assim exposto, o presente trabalho tem como objetivo apresentar uma situação real de toxidez aguda pelo 
BHC em bovinos, na forma de surto; alertar sobre essa contravenção e relatar as ações periciais que foram oportunizadas e implantadas para o diagnóstico da mortalidade, com as respectivas atitudes no sentido de subsidiar reparações e providências.

\section{REVISÃO DE LITERATURA}

De acordo com Paschoal (1979) os primeiros produtos empregados no País para o controle de pragas foram os de origem mineral e os botânicos. O primeiro inseticida orgânico sintético a ser usado foi o DDT, introduzido no Brasil em fins de 1943, sob a denominação de Gesarol. A partir de 1946 outros produtos como o BHC e o Paration etílico foram introduzidos e usados nas lavouras.

A partir da década de 80, o Brasil tornou-se o terceiro consumidor mundial de agrotóxicos, sobre uma estrutura institucional precaríssima, em termos de legislação, armazenamento, pesquisa, fiscalização, comercialização, formação, ética profissional e extensão rural (PASCHOAL, 1983). Os Estados em que o impacto dos praguicidas parece ser mais acentuado, ou pelo menos de que se tem maiores informações, são Rio Grande do Sul, São Paulo e Paraná (PASCHOAL, 1983). No Estado do Paraná, esse consumo tem aumentado significativamente e de forma mais expressiva em cinco culturas principais: batata, cana-de-açúcar, soja, citros e tomate. Segundo o IBGE (1998) o total aplicado nas culturas mencionadas ultrapassou 128 mil toneladas de agrotóxicos.

O BHC é um composto cristalino sintético tendo como característica alta toxicidade, persistência no ambiente e bioacumulação significativa. Tem sido largamente usado como fungicida para proteger as sementes de cebolas, trigo e sorgo. Tem sido ainda utilizado como solvente e como aditivo na produção de borracha, plástico PVC, foguetes, munições, protetores de madeira e corantes (NAKAGAWA, ANDREA, 2005). A produção de BHC já foi 
proibida em muitos países. No entanto, é um subproduto da manufatura de vários solventes clorados, pesticidas e de outros processos que envolvem o cloro. Já foi encontrado como contaminante em diversos pesticidas e é libertado durante a queima da resíduos urbanos (ALCOCK; JONES, 1999).

Os seres humanos, sejam trabalhadores rurais e industriais, bem como a população em geral consumidora dos alimentos, podem ainda ser afetados através da inalação de vapores desse veneno. Em 1825, Michael Faraday verificou que o benzeno $\left(\mathrm{C}_{6} \mathrm{H}_{6}\right)$ reage com cloro quando exposto à luz ultravioleta. A luz quebra as moléculas do gás cloro $\left(\mathrm{Cl}_{2}\right)$, deixando os átomos livres para romper as ligações duplas entre os átomos de carbono do benzeno, adicionando-se a ele. O produto obtido, ou seja o BHC, consiste na mistura de várias substâncias isômeras, isto é, constituídas pelos mesmos tipos e quantidades de átomos, mas que estão organizados de forma diferente (NASS; FRANCISCO, 2002).

Segundo Burse et al. (2000), quando ingerido, este pernicioso agrotóxico, pode prejudicar o fígado, tiróide e rins. Além disso há comprometimento dos sistemas endócrino, imunológico, reprodutivo e nervoso de todos seres vivos que mantenham contato com 0 veneno (EZENDAM et al., 2004). Existem provas de maior susceptibilidade à infecção e do aumento da mortalidade infantil em crianças expostas ao BHC, bem como ser ele causador de mutagênese (LEVIGARD, 2001). Outros efeitos são neurotoxidade retardada, lesões no Sistema Nervoso Central, redução de fertilidade, reações alérgicas, formação de catarata e efeitos teratogênicos, entre outros (COUTO, 2005).

Nass e Francisco (2002) ainda destacaram que o $\mathrm{BHC}$, devido à alta 
toxicidade, tem sido bastante combatido desde os anos 1970 e seu envenenamento em seres humanos pode também ser causado por inalação ou absorção pela pele. A substância tóxica causa desde sonolência até convulsões e colapsos circulatórios, além do câncer.

Como poluente ambiental o BHC é muito destacado em trabalhos e ensaios apresentados por vários autores em vários locais do mundo: Na Alemanha, Áustria e Hungria (GEMMER, 1979); no Brasil (NISHIKAWA et al., 1982 e CARVALHO et al., 1984); no Chile (PINTO et al., 1987); no Panamá (ESPINOSA GONZALEZ; THIEL, 1988); no Marrocos (KESSABI et al., 1990); nos Estados Unidos (SALMAN et al., 1990); na Eslováquia (FEJES; BREYL, SALITROSOVA, 1991); na Polônia (NIEWIADOWSKA; $\quad$ ZMUDZKI; SEMENIUK, 1995); na Dinamarca (BURSE et al., 2000); nas regiões africanas do Senegal e Gâmbia
(MANIRAKIZA et al., 2002); na Espanha (COSTABEBER; SANTOS; TATIANA, 2003); na Grécia (KAMARIANOS et al., 2003a); no México (PARDIO et al., 2003 e WALISZEWSKI et al., 2004); e na Noruega (EZENDAM et al., 2004).

Como todo agrotóxico, o BHC causa interferência sobre a dinâmica dos ecossistemas, como nos processos de quebra da matéria orgânica e de respiração do solo, ciclo de nutrientes e eutrofização de águas (NAKAGAWA; ANDREA, 2005). Os dados de contaminação ambiental que mais parece preocupar a opinião pública nos países desenvolvidos são as contaminações do ar, do solo e principalmente das águas (ANDREOLI; FERREIRA, 1998; NAKAGAWA; ANDREA, 2005).

No que concerne aos efeitos do BHC em animais, a literatura mostra haver situações de efeitos tóxicos em diferentes localidades do mundo. Boa parte dos autores destacam a 
acumulação de resíduos químicos do touros (FEJES; BREYL; BHC em vísceras dos bovinos, SALITROSOVA, 1991; KAMARIANOS causando acumulação em órgãos vitais et al., 2003a), acumulando resíduos tais como fígado e rins (ESPINOSA tóxicos em epidídimo e ovário (FEJES et GONZALEZ; THIEL, 1988; KESSABI et al., 1991), com comprometimento na al., 1990; SALMAN et al., 1990; FEJES; produção de sêmen de bovinos afetados BREYL; SALITROSOVA, 1991); (KAMARIANOS et al., 2003b). Ainda há pulmão, baço e linfonodos (EZENDAM vários estudos demonstrando a et al., 2004); gordura animal (GEMMER, vulnerabilidade do homem frente a 1979; CARVALHO et al., 1984, PINTO riscos epidemiológicos de se et al, 1987, WALISZEWSSKI et al., intoxicaram a partir da ingestão de 2004, MANIRAKIZA et al., 2002); no subprodutos de origem animal, como sangue animal (SALMAN et al., 1990). leite e carne (GEMMER, 1979;

Como causador de grandes

impactos ambientais, o BHC acumula-se no peixe, mamíferos marinhos, aves, líquenes, vegetais e nos animais que se alimentam de todos estes seres vivos, inclusive o homem (BURSE et al., 2000; MANIRAKIZA et al., 2002).

Todavia há relatos de que os animais acometidos por quadros tóxicos brandos, podem ter comprometimento do sistema reprodutivo, tanto em vacas (WALISZEWSKI et al, 2004) quanto em
NISHIKAWA et al., 1982; CARVALHO et al., 1984; NIEWIADOWSKA; ZMUDZKI; SEMENIUK, 1995). O ciclo de toxidez torna-se mais grave ainda a medida em que as constatações residuais (SALMAN et al., 1990; LUSKY, 1992; BURSE et al., 2000; EZENDAM et al., 2004) são evidenciadas em leite de mulheres (COSTABEBER; SANTOS; TATIANA, 2003), causando interferência no sistema imunológico de seres humanos (EZENDAM et al., 2004), com 
alterações comportamentais e carne em conserva (NISHIKAWA et al., cognitivas (BURSE et al., 2000), 1982). Ainda a respeito de efeitos comprometendo significativamente a nocivos a saúde animal, a literatura saúde pública coletiva (BURSE et al., destaca os trabalhos de Lusky et al. 2000; PARDIO et al., 2003; EZENDAM (1992), onde detectou níveis de BHC et al., 2004). A observação da em animais silvestres e a pesquisa de precocidade sintomatológica de toxidez pelo $\mathrm{BHC}$ em animais, podendo servir como modelo sentinela para salvaguardar a saúde de populações foi destacado no trabalho de Salman et al. (1990), com a prerrogativa de monitorar ambientes compartilhados, sobretudo em zonas rurais. Ainda sobre a questão de saúde pública, alguns ensaios demonstraram o risco iminente em se consumir outros sub-produtos que, podem conter níveis de $\mathrm{BHC}$, tais como peixe, camarão e diferentes mamíferos marinhos (MANIRAKIZA et al., 2002); carne suína e de aves (ESPINOSA GONZALEZ; THIEL, 1988; KESSABI et al., 1990); ovos (KESSABI et al., 1990); e na carne bovina (KAMARIANOS et al., 2003a; WALISZEWSKI et al., 2004) e Ezendam et al. (2004), que mensuraram este veneno em fragmentos teciduais de roedores. Ainda, Waliszewski et al. (2004) alertam para o fato de produtos a base de BHC serem utilizados como produto para combater a malária, bem como na composição de medicamentos contra ectoparasitas.

\section{MATERIAL E MÉTODOS}

O caso relatado ocorreu em uma propriedade rural, localizada no distrito de Jussiara, município de Kaloré (Altitude 380,00 metros; Latitude $23^{\circ} 49^{\prime}$ $20^{\prime \prime}$ Sul; Longitude $51^{\circ} 40^{\prime}$ 00" W-GR), Estado do Paraná. A região é caracterizada por clima subtropical úmido mesotérmico, verões quentes com tendência de concentração das chuvas (temperatura média superior a 
$\left.22^{\circ} \mathrm{C}\right)$, invernos com geadas pouco frequentes (temperatura média inferior a $\left.18^{\circ} \mathrm{C}\right)$, sem estação seca definida.

A propriedade rural, em questão, tem aproximadamente 160 hectares de extensão de terra, com 20 hectares de mata permanente, 80 hectares de terras agricultáveis e 60 hectares de pastagem (capim colonião). $\mathrm{Na}$ propriedade, a área agricultável foi arrendada para o cultivo de soja/trigo e a área de pastagem ficou em descanso, visto que na propriedade não havia animais de produção. A propriedade confronta com outras propriedades, ao leste, uma de 100 hectares de terras agricultáveis, ao oeste é delimitada com o município de São Pedro de Ivaí pelo rio Preguiça (Água da Preguiça), ao norte e ao sul com duas propriedades de 30 hectares do mesmo dono, que transfere seu rebanho de uma propriedade para outra, passando o gado pela propriedade em que ocorreu o relato do caso.
O produto foi adquirido pelos proprietários nos anos 70 quando a propriedade desenvolvia basicamente a atividade de cafeicultura. Com o passar dos anos, o produto foi deixando de ser utilizado nas lavouras de café e embora proibido, ficou embalado em sacos de papel, armazenados no interior de uma casa de madeira e uma tulha, que havia sido vendida para um terceiro, que ao levar as madeiras da casa e da tulha, deixou o produto a céu aberto onde os animais de seu vizinho ao norte (17 cabeças), ao serem transferidas para a propriedade ao sul, tiveram contato durante três dias com o produto tóxico ocorrendo a intoxicação dos animais.

Com a ocorrência de óbito de alguns animais e a exploração clínica in loco, foi possivel examinar os animais remanescentes, efetuar marcha semiológica de exploração clínica e realizar ensaios investigativos de necropsia em 11 bovinos, fechando 
assim o "círculo da toxidez", causada pelo veneno BHC.

Interrogatório clínico: Nos animais ainda vivos, em número de 6 bovinos, pelo exame clínico efetuado observouse aumento da excitabilidade e irritabilidade, incoordenação motora, paralisia, contração rápida e constante das pálpebras e olhos com movimentos circulares (nistagmo), ranger de dentes, anorexia, micção frequente, temperatura corporal de $38^{\circ} \mathrm{C}$, taquicardia e taquipnéia. Um animal remanescente, sendo uma vaca de 5 anos de idade, pelagem predominantemente preta, foi medicada com soluções glicofisiológicas, produtos à base de cálcio, protetores hepáticos, e complexos vitamínicos. Não houve sucesso terapêutico e o animal veio a óbito 1 dia após a tentativa de medicação.

Exame Necroscópico: Em 4 animais não houve a possibilidade de examinar as vísceras, devido ao alto grau de autólise. Um total de 11 bovinos foram necropsiados. A técnica de necropsia seguiu as recomendações estabelecidas por Barros (1988).

\section{RESULTADOS}

Os animais que vieram a óbito de forma aguda, totalizaram 15 cabeças de bovinos. Os dados individualizados são demonstrados no Quadro 1, a seguir.

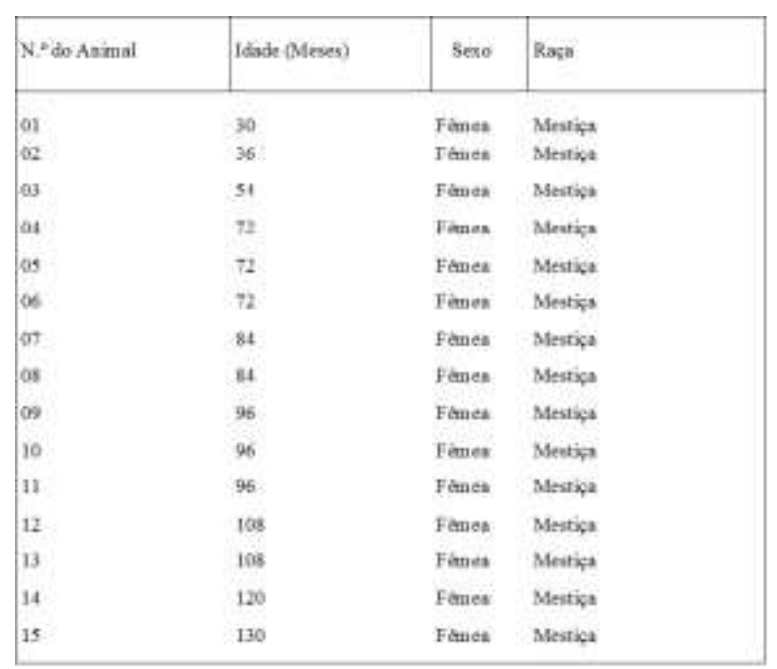

O intervalo entre a morte e a necropsia ocorreu de 1 a 6 dias após o óbito e, pela investigação dos cadáveres, as mortes foram ocorrendo de forma gradativa, porém de modo súbito.

As principais lesões encontradas nas vísceras examinadas, na maioria do animais investigados foram: Arco costal: Face interna de coloração laranja-tijolo; Fígado com coloração marrom escuro; Vesícula biliar de coloração laranja-tijolo e com líquido espesso; Baço com aspecto esbranquiçado; Rins com aspecto gelatinoso de coloração escura, 
tendendo ao negro, que ao ser colocado entre as mãos extravasava pelos dedos; Rúmen com conteúdo de coloração acinzentada. Em alguns animais havia presença de pedaços de papel, que posteriormente, foi comparado com sacos de papel do produto tóxico achados na propriedade, demonstrando a ingestão voluntária e tóxica pelos bovinos. Os demais órgãos dos animais examinados não apresentaram alterações dignas de nota.

\section{DISCUSSÃO}

No Brasil o problema dos agrotóxicos adquire uma dimensão de forte impacto no que diz respeito à Saúde Pública, uma vez que o país situa-se entre os maiores consumidores mundiais de agrotóxicos, o maior da América Latina. Os danos à saúde das populações expostas refletem-se em altos índices de intoxicações e mortes. Os problemas ambientais são expressos na contaminação de solos, de águas superficiais e subterrâneas, na extinção de insetos úteis, de aves e de outras espécies, além da contaminação das cadeias alimentares.

Estudos indicam que a maioria dos casos de intoxicações por agrotóxicos ocorrem, principalmente, devido ao descumprimento das normas de segurança para a sua aplicação, devido a irregularidades no armazenamento e na distribuição dos produtos, assim como à ausência de políticas públicas de controle (HENAO; COREY, 1991).

O convívio com agrotóxicos está incluído na rotina diária da população rural e da população urbana, que consome muitas vezes, inconscientemente alimentos e água com os resíduos destes produtos (MEDEIROS et al., 1988).

A partir dos óbitos dos bovinos e as manifestações de sintomas pela toxidez do BHC em outros animais da mesma propriedade, iniciou-se 0 trabalho de vigilância sanitária, aplicando-se pesquisa para investigar 
todas os aspectos circunscritos ao episódio.

No exame clínico efetuado in loco nos bovinos ainda vivos, constatou-se como manifestação prevalente contração das pálpebras os olhos com movimentos circulares (nistagmo), sendo que alguns animais mostravam aparentemente cegos. Alguns bovinos tinham frequência respiratória aumentada, sintomas clássicos de intoxicação por BHC, conforme descrito por outros autores (BLOOD; HENDERSON; RADOSTITS, 1983).

O resultado análise necroscópica dos 11 animais monitorados demonstrou que as lesões observadas nas vísceras são compatíveis com a descrição de intoxicação pelo $\mathrm{BHC}$, conforme já haviam relatado em outros ensaios (BLOOD; HENDERSON; RADOSTITS, 1983). Os resultados, além de confirmar o quadro clínico de toxidez pelo $\mathrm{BHC}$ nos animais da propriedade rural em foco, reiteraram a necessidade urgente de coibir ações de contrabando desse e de outros venenos.

Do ponto de vista da saúde pública ainda, é sempre oportuno alertar sobre potencial risco aos consumidores de subprodutos de origem animal. No caso do surto de Kaloré é importante lembrar que ainda existem animais vivos que, apesar de ingerirem o veneno, talvez em quantidades pequenas, não vieram a óbito. Todavia, por questão metabólica o princípio tóxico pode atingir a população consumidora, o que torna impróprio o consumo de leite por pessoas, já que o $\mathrm{BHC}$ pode ser eliminado pelo leite (NIEWIADOWSKA; ZMUDZKI; SEMENIUK, 1995; PARDIO et al., 2003). Sobre a ótica da saúde pública, ainda, há, com certeza, em nível mundial, sobretudo nos países que compõem a comunidade europeia uma unanimidade em não se admitir impactos ambientais que causem sequelas e contaminação de alimentos, a partir dos subprodutos de origem 
animal, conforme destacado em direcionar, avaliando criteriosamente Eurepgap (2004). O mundo vive o todos os efeitos maléficos que podem momento verde, ou seja, há uma grande atingir a saúde dos animais, corrente, sobretudo no meio científico, preservando, com isso, a própria saúde de que é possível produzir, mas através de modelos sustentáveis, sem danos ao meio ambiente e aos seres vivos, respeitando a legislação e combatendo o contrabando e uso de produtos agrícolas proibidos. No caso vivenciado em Kaloré, a mortalidade animal deve gerar a necessidade de se fomentar 0 poder judiciário, pois a origem do problema foi devido a uso e armazenagem de agrotóxico proibido no país. O desdobramentos e as consequências foram gravíssimas, inclusive originando atuação pericial de médico veterinário. Neste contexto, cabe destacar que pela experiência, as ações periciais do Médico Veterinário concorreram também em colaborar com a questão ambiental, reforçando os princípios fundamentais para os quais a ciência veterinária pericial deve se pública. Por essa razão entende-se ser plausível referendar a experiência aqui consubstanciada, como sendo um protocolo técnico para essa atuação pericial do Médico Veterinário em ações de biomonitoramento ambiental de ecossistemas, sobretudo para preservar a saúde humana e animal. Por essa razão, não deixa de ser um alinhamento as preocupações da ONU - "Avaliação Ecossistêmica do Milênio" (CIÊNCIA ..., 2005, p.45), em dar a devida divulgação cientifica dos fatos constatados neste episódio para, preventivamente, despertar para outras ações semelhantes pelo pais.

Ainda é mister destacar que do ponto de vista legal, na propriedade em que ocorreu a mortalidade animal, não se pode classificar como acidente, pois a intoxicação pode ser considerada 
presumível, na medida em que se mantém um produto proibido. $A$ isto 0 Código Penal Brasileiro estabelece como denominação de negligência, ou seja, "a inércia psíquica, a indiferença do agente que, podendo tomar as devidas cautelas exigíveis, não o faz por displicência, relaxamento ou preguiça mental" (COUTO, 2005). Além disso, os responsáveis pela manutenção de atos ilegais cometem, à luz da Lei, atos classificados como imperícia, a saber: "é a incapacidade, a falta de habilidades técnicas no exercício de arte ou profissão, não tomando o agente em consideração o que sabe ou deve saber" (BRASIL, 1999). Também se considera tal ato como sendo imprudência, pois trata-se de uma “atitude precipitada do agente, que age com afoiteza, sem cautelas, não usando de seus poderes inibidores, criação desnecessária de um perigo". Essas situações configuram crime, que o que a tornava de difícil aplicação. segundo o Código Penal Brasileiro, Porém na situação de provocar a
Artigo 18, inciso II destaca: "diz-se crime culposo, quando o agente deu causa ao resultado por imprudência, negligência ou imperícia" (BRASIL, 1999).

Além de todas essas contravenções, é oportuno ressaltar que as ações periciais na elucidação de crimes cometidos contra a fauna e meio ambiente, o Médico Veterinário, com especialidade pericial, certamente terá ainda muita contribuição para com as ações interpostas no Judiciário. A base dessa afirmativa é a legislação de preservação da fauna e flora, regida pela Lei de Crimes Ambientais (Lei no 9.605, de 12 de fevereiro de 1998, regulamentada pelo Decreto $\mathrm{n}^{\circ}$ 3.179/99). Esta legislação vem preenchendo um vazio onde o próprio homem não sabia como agir juridicamente, em se tratando de crimes contra a natureza e seus seres vivos, devido ao caráter esparso da antiga Lei, 
contaminação dos animais, pela ao Poder Público e à coletividade o negligência nas ações de produção de dever de defendê-lo e preservá-lo para qualquer tipo de produto, o dano contra as presentes e futuras gerações" a fauna, no caso os animais pecuários, (BRASIL, 2004).

como são os bovinos, é passível de punição pela aplicação da Lei. Além disso, todas as ações que o homem causar de dano ao meio ambiente, serão passíveis de enquadramento (Seção III, Artigos 54 e 56, da Lei de n.․․ 9605, de 12 de fevereiro de 1998), conforme descrito em Brasil (1998).

No Brasil é preciso, imediatamente, cumprir-se a Lei, em toda a sua plenitude, evitar o surto;

contrabando e as contravenções, pois em curto prazo são previsíveis sérios impactos ambientais, irreversíveis do ponto de vista de recursos naturais renováveis. Nunca é demais lembrar que, conforme o Código Civil Brasileiro, Artigo 225: "todos tem direito ao meio ambiente ecologicamente equilibrado, bem de uso comum do povo e essencial à sadia qualidade de vida, impondo-se

\section{CONCLUSÃO}

Pela análise dos resultados e de observações clínicas realizadas, podese concluir:

$1^{\text {a })}$ Os bovinos foram vitimados pela ação tóxica do BHC;

$2^{a}$ ) enquanto existir contrabando de agrotóxicos proibidos no Brasil, há riscos de quadros tóxicos em forma de

3ㄹ) O trabalho pericial do Médico Veterinário em detectar os danos causados ao ambiente e aos animais, constitui-se num poderoso referencial para preservar a saúde pública, sobretudo em localidades críticas, onde existam venenos poluindo o ambiente $\mathrm{e}$ dividindo espaço com seres humanos.

$4^{a}$ ) Do ponto de vista da Saúde Pública, nós consumidores que somos, 
mantemos uma estreita relação na Janeiro: Guanabara Koogan, 1983.

cadeia alimentar com os animais, onde os bovinos criados em zonas rurais e mesmo áreas urbanas são passíveis de intoxicação pela contaminação provocada pelo homem contra sua própria Fauna e Flora, devido ao impacto ambiental irreversível provocado nos recursos naturais renováveis, regida pela portaria № 329 de 2 de Setembro de 1985.

\section{REFERÊNCIAS}

ALCOCK, R. E.; JONES, K. C. New organic compounds in the environment. Atmospheric Environment, Oxford, v. 33, n. 10, p.1645-1646, May 1999.

ANDREOLI, C.V.; FERREIRA, A. C. Levantamento quantitativo de agrotóxicos como base para a definição de indicadores de monitoramento de impacto ambiental na água. Revista SANARE, Curitiba, v.10. n. 10.p. 30-38. 1998.

BLOOD, D. C.; HENDERSON, J. A.; RADOSTITS, $M$. Inseticidas hidrocarbonetos clorados. In:

Clínica veterinária. 5.ed. Rio de p.964-66.

BRASIL. Código Penal. Organização de textos de Antonio Luiz de Toledo Pinto. 37.ed. São Paulo: Saraiva, 1999. (Legislação Brasileira)

BRASIL. Código civil, Código de processo, Constituição Federal. Organização de Joyce Angher. 4.ed. São Paulo: Rideel, 2004.

BRASIL. Lei $n^{\circ} 9.605$, de 12 de fevereiro de 1998. Dispõe sobre as sanções penais a administrativas derivadas de condutas e atividades lesivas ao meio ambiente. Diário Oficial [da] República Federativa do Brasil, Brasília, DF, 12 fev. 1998. Disponível em: http://www.silex.com.br/leis/1_9605.html >. Acesso em: 6 jul. 2005.

BURSE, V.W. et al. Utilization of umbilical cords to assess in utero exposure to persistent pesticides and polychlorinated biphenyls. Journal of Exposure Analysis and Environmental Epidemiology, New York, v.10, n.6, p.776-788, Nov./Dec. 2000.

CARVALHO, J. P. P. et al. Resíduos de praguicidas organoclorados em gordura bovina. O Biológico, São Paulo, v.50, n.2, p.39-48, 1984. 
CIENCIA e Tecnologia no meio ambiente. Isto É, São Paulo, n.1851, p.45-46, abr. 2005.

COSTABEBER, I.; SANTOS, J. S.; E., TATIANA. Relaçäo entre a freqüência de consumo de carne e pescado e os níveis de BHC, lindano, aldrin e 4,4(9)diclorodifenil-1,1(9)dicloroetileno, em tecido adiposo de glândulas mamárias de mulheres espanholas / Relationship between the frequency of meat and fish intake and the levels of hexaclorobenzene, lindane, aldrin e 4,4(9)dichloro diphenil 1,1(9)dichloroethylene, present in mamary adipose tissue samples from spanish women. Ciência Rural, Santa Maria, v.33, n.1, p. 151-153, 2003.

COUTO, José Luis Viana do. Sinais e sintomas do envenenamento por agrotóxicos. Disponível em: $<$ http://www.ufrrj.br/institutos/it/de/aciden tes/vene3.htm>. Acesso em: 10 maio 2005.

ESPINOSA GONZÁLEZ, J.; THIEL, R. Residuos de insecticidas organoclorados en productos nacionales. Revista Médica de Panamá, Panamá, v. 13, n.2, p.111114, 1988.

EUREPGAP. Puntos de control $y$ criterios de cumplimiento aseguramiento integrado de fincas. Konn, GE, jan.2004. Seccion 9: Animales. Disponível em: $<$ http://www.eurep.org/Languages/Englis h/index_html>. Acesso em: 10 maio 2005.

EZENDAM, J. et al. Hexachlorobenzene-induced Immunopathology in Brown Norway Rats is Partly Mediated by $\mathrm{T}$ Cells. Toxicological Sciences, Orlando, v.78, n.1, p.88-95, 2004.

FEJES, J.; BREYL, I.; SALITROSOVA, $\mathrm{H}$. Detection of residues of some foreign substances in bull and cow genital tissues and bull semen. Detekcia rezidui niektorych cudzorodych latok $v$ tkanivach genitalu bykov a krav a $v$ sperme bykov. Veterinarni-Medicina, Praha, v.36, n.4, p.203-211, 1991.

GEMMER, H. Erfahrungen bei der Ueberwachung von Lebensmitteln tierischer Herkunft. Zentralblatt fur Bakteriologie, Parasitenkunde, Infektionskrankheiten und Hygiene, Stuttgart, v.168, n.2, p.144-156, 1979.

HENAO, S.; COREY,G. Plaguicidas inhibidores de las colinesterasas. México: Centro Panamericano de Ecologia Humana y Salud, 1991. (Serie Vigilancia, n. 11)

IBGE. Pesquisa mensal de previsão e acompanhamento das safras agrícolas 
no ano civil. Levant amento Sistemático da Produção Agrícola.

Rio de Janeiro, v.5, n.6, p.1-76, 1998.

KAMARIANOS, A. et al. The presence of environmental pollutants in the follicular fluid of farm animals (cattle, sheep, goats, and pigs). Reproductive Toxicology, Seattle, v.17, n.2, p.185190, 2003a.

KAMARIANOS, A. et al. The presence of environmental pollutants in the semen of farm animals (bull, ram, goat, and boar). Reproductive Toxicology, Seattle, v.17, n.4, p.439-445, 2003b.

KESSABI, M. et al. Contamination of eggs, poultry liver and bovine liver and kidney by chlorinated pesticides in Morocco. Science of the Total Environment, Amsterdam v.90, p. 283287, 1990.

LEVIGARD, Y. E. A interpretação dos profissionais de saúde acerca das queixas do nervoso no meio rural: uma aproximação ao problema das intoxicações por agrotóxicos. 2001. Dissertação (Mestrado) - Fundação Osvaldo Cruz, Rio de Janeiro.

LUSKY, K. et al. A. Studies in environmental contaminants in wild boars, red deer, roe deer, mouflon, and fallow deer from the Schorfheide-Chorin biosphere reservation. Archiv-fur-
Lebensmittelhygiene, Hannover, v.43, n.6, p.131-136, 1992.

MANIRAKIZA, P. et al. Persistent chlorinated pesticides in fish and cattle fat and their implications for human serum concentrations from the SeneGambian region. Journal of Environmental Monitoring, Cambridge, v.4, n.4, p.609-617, 2002.

MEDEIROS, M. L. M. B. et al. Problemática de agrotóxicos no Paraná. Curitiba: SUREHMA, 1988. 14 p.

NAKAGAWA, L. E.; ANDRÉA, M.M Volatilização e lixiviação de ${ }_{14} C$ hexaclorobenzeno em solo contaminado. Arquivos do Intituto Biológico, São Paulo, v.72, n.2, p.255260, abr./jun.2005.

NASS, D.P. ; FRANCISCO, R.H.P., Fim de doze poluentes orgânicos. Revista Eletrônica de Ciências, São Carlos, n.5, 2002. Artigo disponível em: $<$ http://www.cdcc-

sc.usp.br/ciências/artigos/art-

5/fimpoluente.html>. Acesso em: 10/06/ 2005.

NIEWIADOWSKA, A.; ZMUDZKI, J.; SEMENIUK, S. Residues of chlorinated hydrocarbons in milk. Pozostaosci cholorowanych weglowodorow aromatycznych w mleku. Roczniki- 


\section{Panstwowego Zakadu-Higieny,}

Warszawa, v.46, n.2, p.113-117, 1995.

NISHIKAWA, A. M. et al. Níveis de resíduos de praguicidas organoclorados em conserva de carne bovina. 0

Biológico, v.48, n.8, p.189-193, 1982.

PARDIO, V. T.et al. Organochlorine pesticide residues in cow's milk from a tropical region of Mexico. Food Additives \& Contaminants, London, v.20. n.3, p.259-269, 2003.

PASCHOAL, A.D. Biocidas: morte a curto e a longo prazo. Revista Brasileira de Tecnologia, Brasília, v. 14, n.1, p.24-40, 1983.

PINTO, C. M. et al. Determinacion de residuos de pesticidas organoclorados en grasa perirenal de bovinos. AgroSur, Wymysłów, v.15, n.2, p. 62-74, 1987.

SALMAN, M. D. et al. Chlorinated hydrocarbon insecticides in Colorado beef cattle serum- a pilot environmental monitoring system. Journal of Toxicology an Environmental Health, Washington, v.31, n.2, p.125-132, 1990. WALISZEWSKI, S. M. et al. Persistent organochlorine pesticide levels in bovine fat from Mexico. Food Additives \& Contaminants, New York, v.21, n.8, p.774-780, 2004. 


\section{APENDICES}



Figura 1- Vista da propriedade (local onde se encontrava o produto tóxico).

Figura 2 - Material tóxico encontrado no local e diversas embalagens.
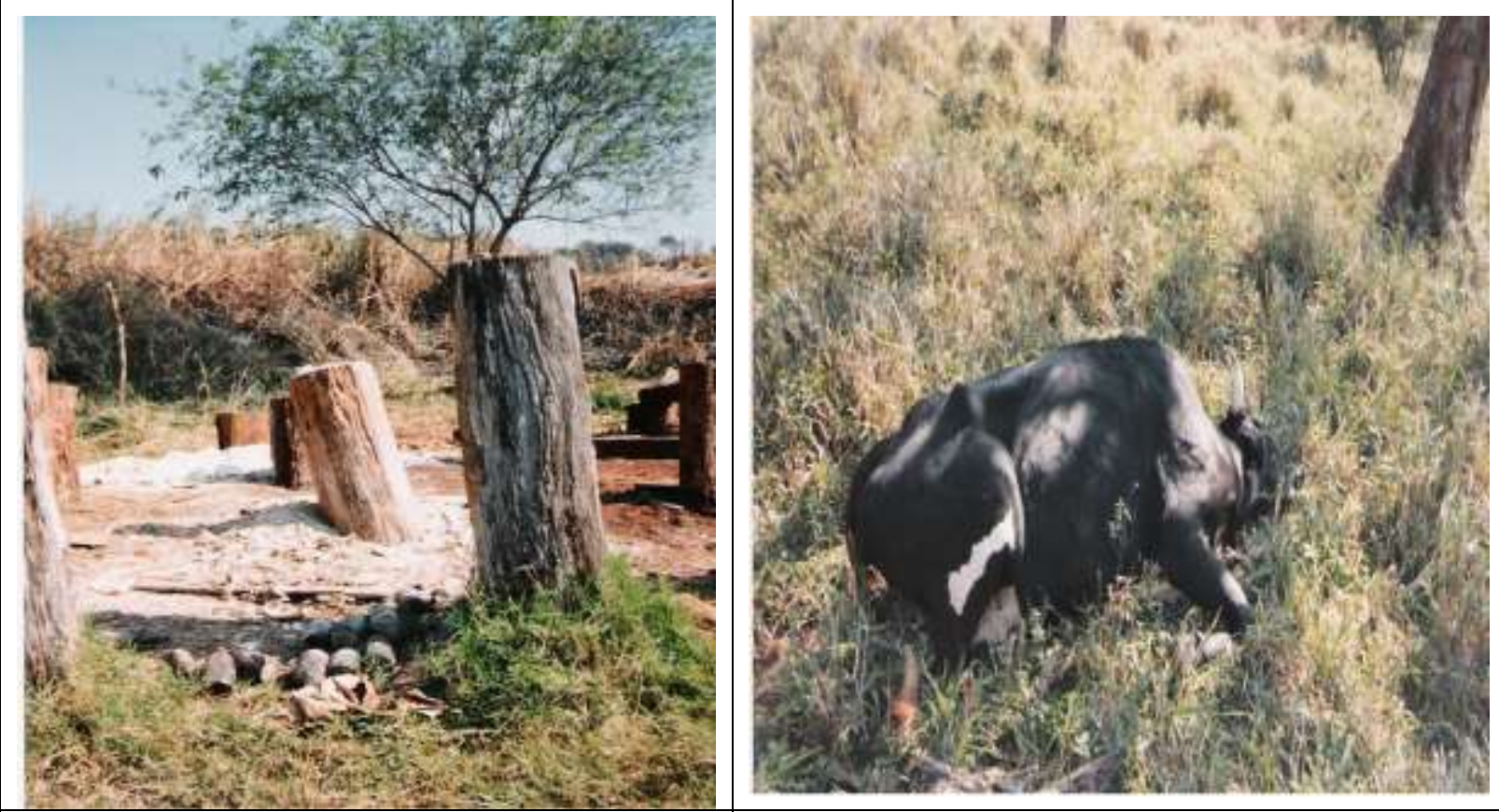

Figura 3 - Vista aproximada da quantidade de produto tóxico

Figura 4 - Bovino com sintomatologia nervosa. 


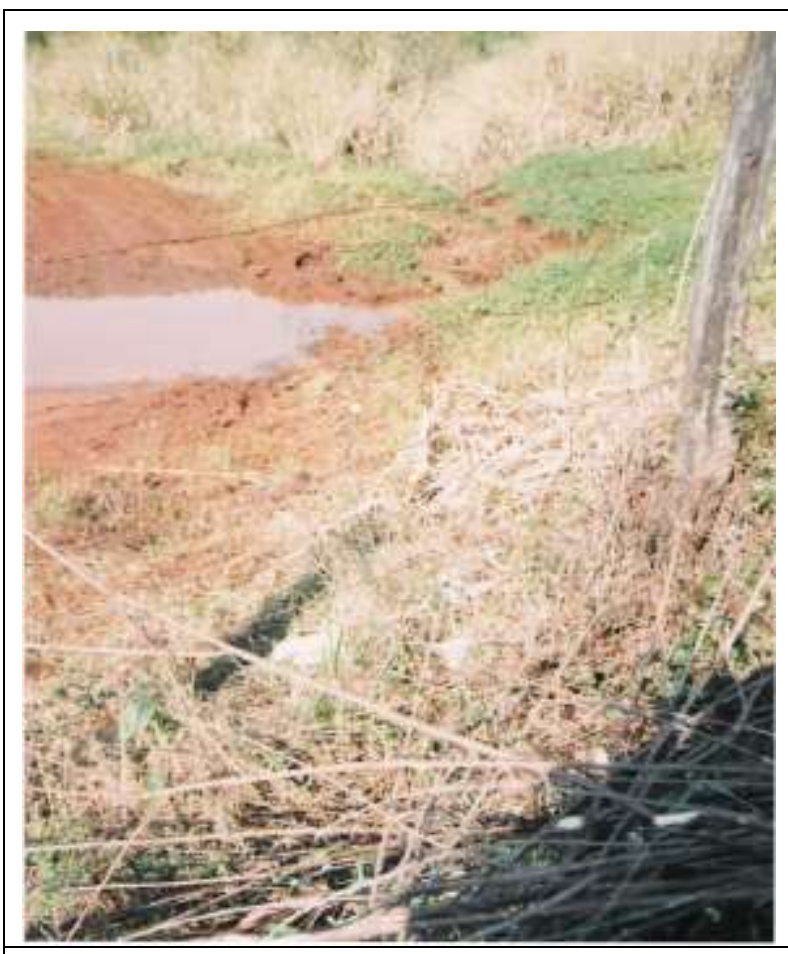

Figura 5 - Mananciais contaminados: problemas ambientais.
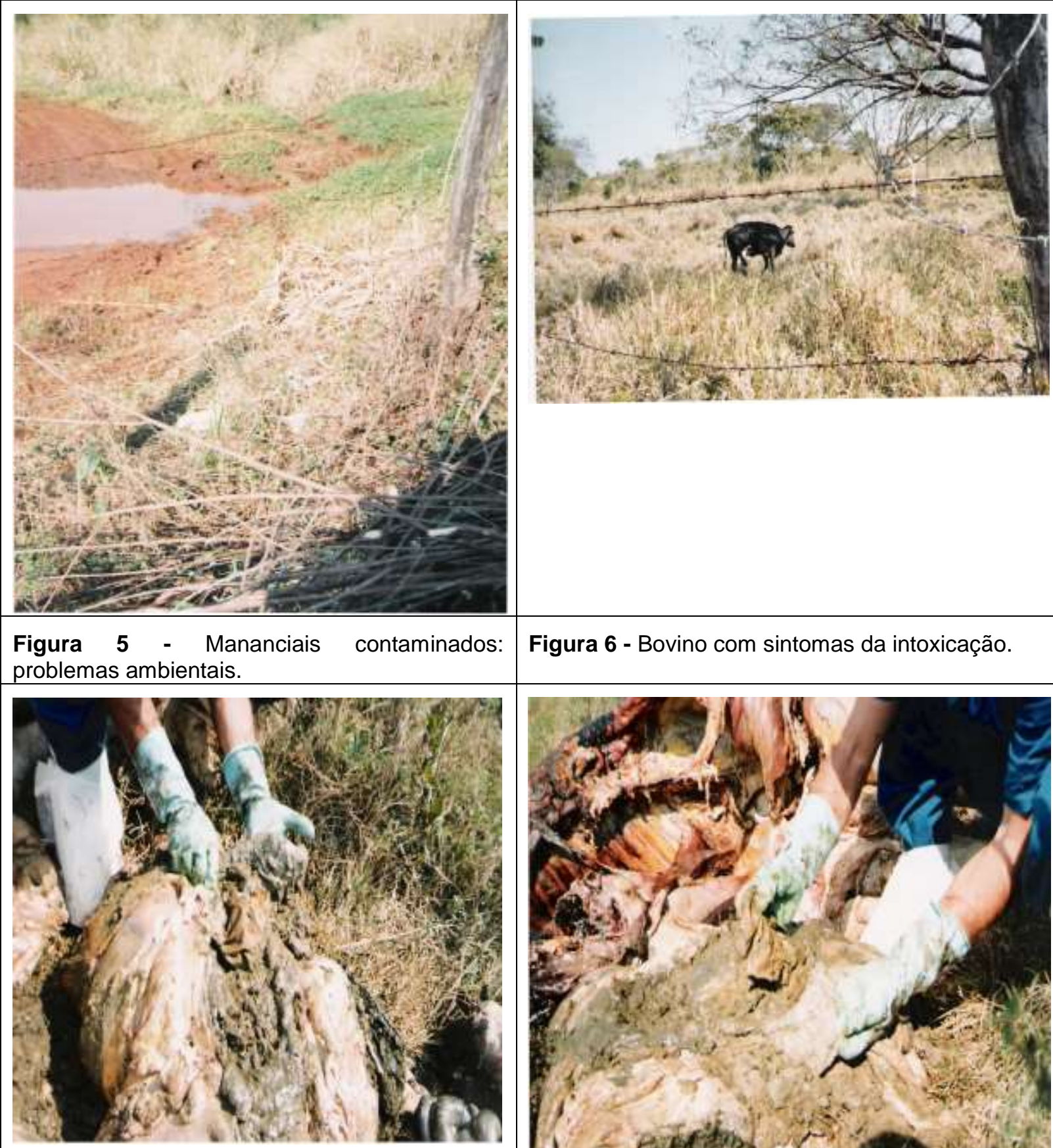

Figura 6 - Bovino com sintomas da intoxicação.

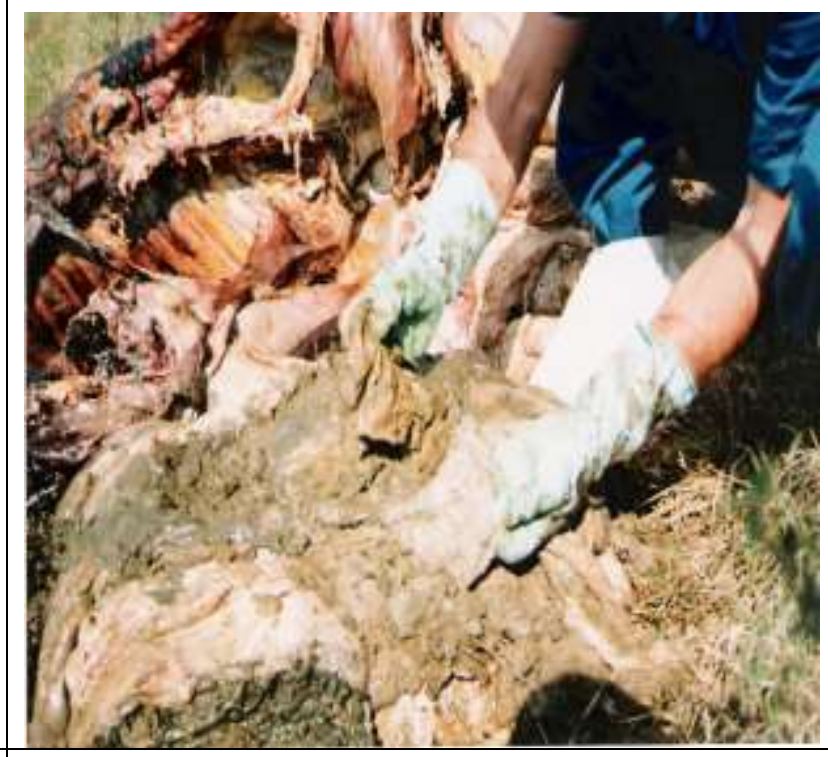

Figura 7 - Material tóxico encontrado no rumem do animal (vaca).

Figura 8 - Embalagem do produto tóxico dentro do rumem do animal (vaca). 
ANEXO

Portaria no 329, de 02 de setembro de 1985

O Ministro de Estado da AGRICULTURA, no uso das suas atribuições que Ihe confere o Capítulo VI e, especificamente, o Art. 143 do Regulamento aprovado pelo Decreto $\mathrm{n} \times 24.114$, de 12 de abril de 1934, e considerando a necessidade de resguardar a saúde humana e animal e o meio ambiente da ação de agrotóxicos, comprovadamente de alta persistência e/ou periculosidade resolve:

B 1ํ - Proibir, em todo o território nacional, a comercialização, o uso e a distribuição dos produtos agrotóxicos organoclorados, destinados à agropecuária, dentre outros: ALDRIN, BHC, CANFENO CLORADO (TOXAFENO), DDT, DODECACLORO, ENDRIN, HEPTACLORO, LINDANE, ENDOSULFAN, METOXICLORO, NOMACLORO, PENTACLOROFENOL, DICOFOL e CLOROBENZILATO.

Parágrafo Único - constituem exceção à proibição constante deste artigo:

a) o uso de iscas formicidas à base de Aldrin e Dodecacloro;

b) o uso de cupinicidas à base de Aldrin para o emprego em florestamento e reflorestamento;

c) o uso dos referidos produtos quando aplicados pelos órgãos públicos competentes, em campanhas de saúde pública de combate a vetores de agentes etiológicos de moléstias;

d) o uso emergencial na agricultura, a critério da Secretaria Nacional de Defesa Agropecuária - SNAD - do Ministério da Agricultura.

2ำ - Admitir a comercialização, o uso e a distribuição de produtos do princípio ativo PARAQUAT somente sob a forma de venda aplicada.

3ำ - Esta Portaria entra em vigor na data de sua publicação, revogando disposições em contrário. 